\title{
The effect of different meals on the absorption of stable isotope-labelled phylloquinone
}

\author{
Kerry S. Jones*, Les J. C. Bluck, Laura Y. Wang, Alison M. Stephen, Celia J. Prynne and W. Andy Coward † \\ MRC Human Nutrition Research, Elsie Widdowson Laboratory, Fulbourn Road, Cambridge CB1 9NL, UK
}

(Received 23 October 2008 - Revised 24 March 2009 - Accepted 14 April 2009 - First published online 19 June 2009)

Few studies have investigated the absorption of phylloquinone (vitamin $\mathrm{K}_{1}$ ). We recruited twelve healthy, non-obese adults. On each study day, fasted subjects took a capsule containing $20 \mu \mathrm{g}$ of ${ }^{13} \mathrm{C}$-labelled phylloquinone with one of three meals, defined as convenience, cosmopolitan and animal-oriented, in a three-way crossover design. The meals were formulated from the characteristics of clusters identified in dietary pattern analysis of data from the National Diet and Nutrition Survey conducted in 2000-1. Plasma phylloquinone concentration and isotopic enrichment were measured over $8 \mathrm{~h}$. Significantly more phylloquinone tracer was absorbed when consumed with the cosmopolitan and animal-oriented meals than with the convenience meal $(P=0.001$ and 0.035 , respectively). Estimates of the relative availability of phylloquinone from the meals were: convenience meal $=1 \cdot 00$; cosmopolitan meal $=0 \cdot 31$; animal-oriented meal $=0 \cdot 23$. Combining the tracer data with availability estimates for phylloquinone from the meals provides overall relative bioavailability values of convenience $=1 \cdot 00$, cosmopolitan $=0.46$ and animal-oriented $=0.29$. Stable isotopes provide a useful tool to investigate further the bioavailability of low doses of phylloquinone. Different meals can affect the absorption of free phylloquinone. The meal-based study design used in the present work provides an approach that reflects more closely the way foods are eaten in a free-living population.

GC/MS: Bioavailability: Dietary pattern analysis

The earliest discovered biological action of vitamin $\mathrm{K}$ was the control of blood coagulation and consequently dietary guidelines in the $\mathrm{UK}^{(1)}$ and elsewhere ${ }^{(2)}$ are typically based on this function alone. However, it is now recognised that vitamin $\mathrm{K}$ has a much broader physiological role. Phylloquinone is the primary source of vitamin $\mathrm{K}$ in Western diets and average intakes in the UK are about $70 \mu \mathrm{g} / \mathrm{d}^{(3)}$. While these levels are sufficient for the maintenance of normal blood coagulation, they may be insufficient for maximal vitamin D-dependent carboxylation of osteocalcin ${ }^{(4,5)}$ and matrix Gla protein ${ }^{(6)}$. It has been suggested that higher phylloquinone intakes may be beneficial for bone health since they are associated with increased bone mineral density ${ }^{(7)}$ and lower fracture rates ${ }^{(8,9)}$; however, the conclusions from observational studies are generally not supported by more recent intervention data ${ }^{(5,10-12)}$.

Where intakes may be marginal, and in order to set evidence-based dietary recommendations, it is important to understand the relationship between intake and nutrient status. For phylloquinone, the relationship between intake and plasma concentration, although significant, is not very strong ${ }^{(13)}$. An important consideration for the intake-status relationship is the bioavailability, an understanding of which is essential for the determination of the dietary quantity of a nutrient required to ensure adequate status and hence optimal health. In addition, information on phylloquinone bioavailability may be important in controlling coagulation in individuals on long-term anticoagulation treatment ${ }^{(14-16)}$.

Phylloquinone is found in a wide range of foods but vegetables provide over half of daily phylloquinone intake $^{(3,17)}$. Green leafy vegetables are considered the major source of phylloquinone contributing about $20 \%$ to daily intake. Some types of oils and fats also contain high amounts of phylloquinone ${ }^{(18)}$, and due to their widespread use in many food products it is likely that these make an important contribution $^{(3)}$. However, limited information is available on phylloquinone bioavailability from these different sources partly because of the difficulties associated with the analysis of phylloquinone. The majority of studies have compared absorption from different sources to standards, such as Konakion ${ }^{\circledR(19-21)}$, but the results are difficult to compare because of differences in study protocols. The studies have been limited to comparisons of bioavailability from foods given to small numbers of subjects, and often using relatively large vitamin doses. Studies comparing the relative bioavailability of phylloquinone from vegetable and oil sources have produced conflicting results ${ }^{(22,23)}$, most likely due to the different methods used to measure absorption.

The use of stable isotope-labelled tracers potentially avoids some of these problems and provides a safe method

Abbreviation: AUC, area under the curve.

* Corresponding author: Dr Kerry S. Jones, fax +44 1223 437515, email kerry.jones@mrc-hnr.cam.ac.uk

$\dagger$ Dr Andy Coward passed away on 3 November 2007. 
of investigating absorption and bioavailability ${ }^{(24-26)}$. The use of intrinsically labelled vegetables has been investigated for the measurement of phylloquinone absorption ${ }^{(27-29)}$, but this method of labelling is only suitable for single food items that are amenable to labelling in this way.

Bioavailability studies that focus on absorption from single food items may not reflect the true state of affairs in normal meal consumption since they do not take account of interactions between food components that may negate variation in bioavailability between single foods. Based on recent work in our laboratory ${ }^{(30,31)}$, we report here the development and application of a stable isotope-based method to measure phylloquinone absorption. Our initial aim was to determine the fraction of phylloquinone absorbed from test meals by using the labelled phylloquinone as a standard. However, because the meal significantly influenced absorption of the tracer we have presented the data as a meal effect, defined as the influence of the integrated meal on the absorption of free phylloquinone, and a matrix effect that describes the extraction efficiency or bioaccessibility of phylloquinone from the meal components. In order to provide an objective basis for the meal composition used in the present studies, the test meals were designed to reflect dietary clusters identified from the National Diet and Nutrition Survey of adults 2000-1 ${ }^{(32)}$.

\section{Methods}

\section{Subjects}

Twelve healthy, non-smoking subjects were recruited (five female and seven male). The subjects were aged 31.3 (SD 8.3) years (range 22-49 years), with a mean weight of 69.4 (SD 9.3) kg, and BMI of 23.1 (SD 2.3) kg/m². Ethical permission for the study was obtained from the Suffolk Local Research Ethics Committee and informed, written consent was obtained from all subjects.

\section{Stable isotope-labelled phylloquinone}

Methyl- ${ }^{13} \mathrm{C}$-labelled phylloquinone was synthesised by ARC Laboratories (Apeldoorn, The Netherlands). Isotopic purity, assessed by GC/MS in our laboratory, was $>98 \%$. The molecular weight of naturally occurring, unlabelled phylloquinone is $450 \mathrm{Da}$ and for the labelled material $451 \mathrm{Da}$. A stock solution of $83.8 \mathrm{mg}$ in $100 \mathrm{ml}$ of ethanol was prepared, divided into aliquots and stored at $-18^{\circ} \mathrm{C}$. To prepare the dose for volunteers, $48 \mu \mathrm{l}$ of the standard solution was added to $1 \mathrm{ml}$ of groundnut oil to give a solution of $40 \mu \mathrm{g} / \mathrm{ml}$. Ethanol was evaporated from the oil by heating at $35^{\circ} \mathrm{C}$ under $\mathrm{N}_{2}$ with a Pierce Reacti-therm heating block and Reacti-vap evaporator (Perbio Science, Erembodegem, Belgium). After vortexing for $1 \mathrm{~min}, \quad 0.5 \mathrm{ml}$ of groundnut oil containing $20 \mu \mathrm{g}$ $(44.4 \mathrm{nmol})$ of phylloquinone was transferred to a gelatine capsule (kindly provided by Capsugel, Colmar, France). Capsules were prepared fresh for each subject and stored, refrigerated, in amber medicine bottles.

\section{Experimental protocol}

Since recent phylloquinone intake has an effect on plasma phylloquinone concentration, before each study day, volunteers were supplied with a standard evening meal and asked not to eat anything else. The meal consisted of a pizza containing no ingredients known to be high in phylloquinone. On three occasions, at least 2 weeks apart, volunteers attended the volunteer suite at MRC Human Nutrition Research after an overnight fast. An indwelling cannula was inserted into a forearm, and two baseline blood samples were collected into $7.5 \mathrm{ml}$ EDTA S-monovettes ${ }^{\circledR}$ (Sarstedt Ltd, Leicester, UK). The volunteer then took the phylloquinone capsule (with water) immediately preceding consumption of one of three test meals. Previously prepared meals were defrosted overnight and reheated before consumption. In this three-period study, and to minimise sequence effects, subjects were randomised for the order they received the meals, with two subjects designated to each sequence. A snack (two slices of toast with sunflower spread and jam) was provided after $5 \mathrm{~h}$ and water was permitted throughout the study. Thirteen $7.5 \mathrm{ml}$ blood samples were collected at $1 \cdot 0,2 \cdot 0,2 \cdot 5,3 \cdot 0,3 \cdot 5,4 \cdot 0,4 \cdot 5,5 \cdot 0,5 \cdot 5,6 \cdot 0,6 \cdot 5,7 \cdot 0$ and $8.0 \mathrm{~h}$ post-dose. Samples were stored on ice and protected from light and within $1 \mathrm{~h}$ were centrifuged at $4^{\circ} \mathrm{C}$ for $20 \mathrm{~min}$ at approximately $2000 \mathrm{~g}$. Plasma was divided into aliquots and stored at $-70^{\circ} \mathrm{C}$ until analysis.

\section{Meal design}

Each of the three meals was formulated to represent a meal from typical UK dietary patterns. Dietary pattern analysis of data from the National Diet and Nutrition Survey of adults 2000-1 has previously identified four dietary clusters for women and six for men, each characterised by their consumption of each of twenty-five food groups relative to the study population $^{(32)}$. Of these clusters, three showed similar patterns for both men and women and were chosen for the meal design. Fahey et al. ${ }^{(32)}$ assigned a name to each of the dietary clusters to describe its defining characteristics. These names are repeated here in order to aid identification. The 'convenience' cluster is characterised by higher than average consumption of fast foods and refined cereals and lower than average consumption of fruit, vegetables and whole-grain cereals. The cosmopolitan cluster is characterised by higher than average consumption of fruits, vegetables, whole grains, fish and dairy foods and the animal-oriented cluster is characterised by higher than average consumption of red meat and saturated fat. The three test meals were designed to reflect the dietary characteristics of each cluster and, on the basis of food composition data contained equal amounts of phylloquinone $(40 \mu \mathrm{g})$, energy $(3200 \mathrm{~kJ})$, energy from protein $(20 \%)$, fat $(40 \%)$ and carbohydrate $(40 \%)$ and fibre $(10 \cdot 5 \mathrm{~g})$. The meals were chicken pie with beans and chips (convenience), fish pie (cosmopolitan) and beef lasagne (animal-oriented). Dietary composition was estimated using the MRC Human Nutrition Research in-house suite of programs based on McCance and Widdowson's The Composition of Foods, 4th edition $^{(33)}$, its supplements ${ }^{(34,35)}$ and the 6 th edition $^{(36)}$. Phylloquinone values were derived from the 6 th edition ${ }^{(36)}$, published values ${ }^{(18)}$ and unpublished results (C Bolton-Smith and $M$ Shearer). Meal composition is shown is Table 1. Each meal type was prepared in a single batch, cooked and frozen until required. 
Table 1. Weight and nutritional information for the convenience (a), cosmopolitan (b) and animal-oriented (c) test meals

\begin{tabular}{|c|c|c|c|c|c|c|c|}
\hline Ingredient & Weight (g) & Energy (kJ) & Protein (g) & Fat $(g)$ & $\mathrm{CHO}(\mathrm{g})$ & Fibre (g) & Phylloquinone $(\mu \mathrm{g})$ \\
\hline \multicolumn{8}{|l|}{ (a) Convenience meal } \\
\hline Chicken, light meat, raw & 95 & 427 & $22 \cdot 8$ & $1 \cdot 1$ & 0.0 & 0.0 & 0.0 \\
\hline Baked beans & 70 & 249 & 3.6 & 0.4 & $10 \cdot 7$ & 4.8 & 1.9 \\
\hline Milk, whole & 65 & 179 & $2 \cdot 1$ & 2.5 & $3 \cdot 1$ & 0.0 & 0.4 \\
\hline Oven chips, frozen, baked & 60 & 414 & 1.9 & 2.5 & $18 \cdot 0$ & 1.7 & $2 \cdot 8$ \\
\hline Bread, white & 40 & 402 & 3.3 & 0.8 & $19 \cdot 7$ & 1.5 & 0.2 \\
\hline Flour, self-raising & 35 & 491 & $3 \cdot 1$ & 0.4 & $26 \cdot 5$ & 1.4 & 0.3 \\
\hline Margarine (soya based) & 25 & 677 & $\operatorname{Tr}$ & $18 \cdot 3$ & 0.1 & $\operatorname{Tr}$ & 19.5 \\
\hline Onions & 20 & 19 & 0.2 & $\operatorname{Tr}$ & $1 \cdot 0$ & 0.3 & 0.1 \\
\hline Peas, frozen & 18 & 52 & 1.0 & 0.2 & 1.7 & 1.3 & $5 \cdot 2$ \\
\hline Rapeseed oil & 9 & 333 & $\operatorname{Tr}$ & $9 \cdot 0$ & $\operatorname{Tr}$ & 0.0 & $10 \cdot 1$ \\
\hline Total & 437 & 3243 & $38 \cdot 1$ & $35 \cdot 1$ & $80 \cdot 8$ & 11.0 & 40.5 \\
\hline \multicolumn{8}{|l|}{ (b) Cosmopolitan meal } \\
\hline Potatoes, boiled & 260 & 796 & $4 \cdot 7$ & 0.3 & $44 \cdot 2$ & 3.6 & $2 \cdot 4$ \\
\hline Green beans, boiled & 84 & 78 & 1.5 & 0.4 & $2 \cdot 4$ & $2 \cdot 4$ & $32 \cdot 7$ \\
\hline Bread, wholemeal & 65 & 601 & $6 \cdot 1$ & 1.7 & $27 \cdot 1$ & $4 \cdot 8$ & 1.7 \\
\hline Milk, semi-skimmed & 50 & 99 & $1 \cdot 8$ & 0.9 & $2 \cdot 4$ & 0.0 & 0.1 \\
\hline Haddock, smoked, raw & 50 & 173 & 9.5 & 0.3 & 0.0 & 0.0 & $\operatorname{Tr}$ \\
\hline Salmon, raw & 45 & 337 & $9 \cdot 1$ & $5 \cdot 0$ & 0.0 & 0.0 & 0.1 \\
\hline Cream, double & 25 & 462 & 0.4 & $12 \cdot 0$ & 0.7 & 0.0 & 1.6 \\
\hline Cheese, cheddar & 20 & 342 & $5 \cdot 1$ & $6 \cdot 9$ & 0.0 & 0.0 & 0.9 \\
\hline Fat $(70 \%)$ spread & 5 & 130 & 0.0 & 3.5 & 0.0 & 0.0 & 0.7 \\
\hline Butter & 4 & 121 & $\operatorname{Tr}$ & 3.3 & $\operatorname{Tr}$ & 0.0 & 0.3 \\
\hline Flour, plain & 4 & 58 & 0.4 & 0.1 & $3 \cdot 1$ & $0 \cdot 1$ & $\operatorname{Tr}$ \\
\hline Total & 612 & 3197 & 38.6 & 34.4 & 79.9 & 10.9 & 40.5 \\
\hline \multicolumn{8}{|l|}{ (c) Animal-oriented } \\
\hline Tomatoes, canned & 160 & 110 & 1.6 & 0.2 & $4 \cdot 8$ & $1 \cdot 3$ & $9 \cdot 6$ \\
\hline White bread & 95 & 955 & 7.9 & 1.9 & $46 \cdot 9$ & 3.5 & 0.4 \\
\hline Beef, lean, raw & 95 & 490 & $19 \cdot 2$ & 4.4 & 0.0 & 0.0 & 0.3 \\
\hline Milk, whole & 70 & 192 & $2 \cdot 3$ & $2 \cdot 7$ & 3.3 & 0.0 & 0.4 \\
\hline Lasagne, boiled & 70 & 298 & $2 \cdot 1$ & 0.4 & $15 \cdot 4$ & $1 \cdot 0$ & $\operatorname{Tr}$ \\
\hline Peas, frozen & 60 & 168 & 3.4 & 0.6 & $5 \cdot 6$ & 4.2 & $17 \cdot 4$ \\
\hline Onions & 20 & 19 & 0.2 & 0.0 & 1.0 & 0.3 & 0.1 \\
\hline Olive oil & 18 & 666 & 0.0 & $18 \cdot 0$ & 0.0 & 0.0 & $10 \cdot 4$ \\
\hline Tomato purée & 10 & 29 & 0.5 & 0.0 & 1.3 & 0.0 & 0.8 \\
\hline Fat $(70 \%)$ spread & 5 & 130 & 0.0 & 3.5 & 0.0 & 0.0 & 0.7 \\
\hline Butter & 4 & 121 & $\mathrm{Tr}$ & 3.3 & $\operatorname{Tr}$ & 0.0 & 0.3 \\
\hline Flour, plain & 4 & 58 & 0.4 & 0.1 & $3 \cdot 1$ & 0.1 & $\operatorname{Tr}$ \\
\hline Total & 611 & 3236 & 37.6 & 35.0 & 81.4 & $10 \cdot 4$ & $40 \cdot 4$ \\
\hline
\end{tabular}

$\mathrm{CHO}$, carbohydrate; $\mathrm{Tr}$, trace.

\section{Analysis of phylloquinone in meals}

The extraction of phylloquinone from the meals was based on the method described by Booth et al. ${ }^{(37)}$. Quantification was performed by the standard addition method. Chemicals were purchased from VWR (VWR International Ltd, Poole, UK). One meal from each batch was defrosted and heated in the same way as for the subjects' meals, then blended with an equal amount of warm purified water. A $30 \mathrm{~g}$ portion was homogenised using an IKA Ultra Turrax T25 basic homogeniser (Esslab, Essex, UK) and $2 \mathrm{~g}$ of the homogenised meal was transferred to a pestle and mortar and ground with $18 \mathrm{~g}$ of anhydrous sodium sulphate. One gram of the mixture was weighed into a $50 \mathrm{ml}$ polypropylene centrifuge tube (Sarstedt Ltd) and $30 \mathrm{ml}$ of 2-propanol-hexane (3:2, v/v) and $10 \mathrm{ml}$ of purified water were added. At this stage, $3 \mathrm{ng}$ of phylloquinone (Supelco, Poole, Dorset, UK) in $100 \mu \mathrm{l}$ of hexane was added to half the tubes and to the remaining tubes was added $100 \mu \mathrm{l}$ of hexane only. The tubes were vortexed for $3 \mathrm{~min}$ and then sonicated for $3 \mathrm{~min}$ with a Microsonix XL2000 model with 1/8 in. tapered microtip (Microsonix, New York, NY, USA). The tubes were further vortexed for $3 \mathrm{~min}$ and then centrifuged at $2000 \mathrm{~g}$ for $5 \mathrm{~min}$. From the top layer, $9 \mathrm{ml}$ of hexane was removed and transferred to a disposable culture tube $(16 \times 100 \mathrm{~mm}$, Corning Ltd, Hemel Hempstead, UK) and evaporated under $\mathrm{N}_{2}$ at $45^{\circ} \mathrm{C}$. The contents of the tube were reconstituted in $300 \mu \mathrm{l}$ of hexane and further purified by solid-phase extraction using $500 \mathrm{mg}$ silica columns (Sep-Pak-RC ${ }^{\mathrm{TM}} 500 \mathrm{mg}$ silica, Waters, Hatfield, Hertfordshire, UK). The columns were conditioned with $4 \mathrm{ml}$ diethyl ether-hexane $(3 \cdot 5: 96 \cdot 5 \mathrm{v} / \mathrm{v})$ and then $4 \mathrm{ml}$ of hexane. The sample was added and washed with $6 \mathrm{ml}$ of hexane before elution with $7 \mathrm{ml}$ of diethyl ether-hexane $(3 \cdot 5: 96 \cdot 5, \mathrm{v} / \mathrm{v})$. The use of a $\mathrm{C} 18$ solid phase extractor purification step was also investigated, but significant losses occurred during the washing steps and we found silica solid phase extractor alone provided sufficient purification. The sample eluent was collected into disposable glass tubes $(13 \times 100 \mathrm{~mm}$, Fisher Scientific Ltd, Loughborough, Leics, UK) and evaporated to dryness in a vacuum evaporator (Savant, New York, NY, USA). The samples were reconstituted in $200 \mu \mathrm{l}$ of dichloromethane and $800 \mu \mathrm{l}$ of methanol and analysed by HPLC. Extraction and analysis was performed in duplicate. 


\section{Quantitative analysis}

Meal and total plasma phylloquinone were measured by HPLC with fluorescence detection after post-column reduction ${ }^{(38)}$. Long-term reproducibility of quality control plasma samples was assessed by their analysis in parallel with the unknowns to ensure the quality assurance in routine analysis. The lower limit of detection of phylloquinone by the described HPLC method is $0.04 \mathrm{nmol} / \mathrm{l}^{(38)}$. The inter-assay $\mathrm{CV}$ of lyphilised human plasma standards (Immunodiagnostik AG, Bensheim, Germany) were $4.3 \%$ (mean $0.48 \mathrm{nmol} / 1, n$ ) and $1.7 \%$ (mean $1.50 \mathrm{nmol} / 1, n 8$ ). The laboratory also participates in the vitamin $\mathrm{K}$ external quality assurance scheme run by the Human Nutristasis Unit at St Thomas' Hospital.

\section{Isotope ratio analysis}

Isotope ratio measurements of phylloquinone in plasma were performed by GC/MS after extraction and derivatisation as described previously ${ }^{(30)}$. Briefly, sample extraction and clean-up was achieved by enzyme hydrolysis with lipase and cholesterol esterase, deproteination with ethanol, extraction with hexane and solid-phase extraction. Isotopic composition was determined in the pentafluoropropionyl derivative of phylloquinone. Analysis was performed on an Agilent GC/MS 5973N inert system (Agilent Technologies, Stockport, UK) comprising a $6890 \mathrm{GC}$ with autosampler and equipped with on-column injection. The chromatography used a DB5-MS fused-silica capillary column $(15 \mathrm{~m} \times 0.25 \mathrm{~mm}$ inner diameter, $0.25 \mu \mathrm{m}$ film thickness). Ions $598.4 \mathrm{~m} / \mathrm{z}$ to $602.4 \mathrm{~m} / \mathrm{z}$ (M to $\mathrm{M}+4$ ) were monitored in selected ion monitoring and highresolution mode. Isotope ratios and thus tracer concentrations were calculated using the $\mathrm{M}+1 / \mathrm{M}(599.4 / 598.4 \mathrm{~m} / \mathrm{z})$ ratio. The limit of quantification of the GC/MS method is $0.3 \mathrm{nmol} / 1$ of total phylloquinone (labelled + unlabelled (endogenous and from the meal) and inter-assay precision is about $3 \%^{(30)}$. Isotopomer ratios were calculated using the fitting methods of Bluck \& Coward $^{(39)}$ from the raw data generated by the GC/MS.

\section{Calculations}

Area under the curve (AUC) was used to assess absorption of the labelled phylloquinone tracer and was calculated using the trapezoid rule. Tracer AUC data assessed the effect of the meal on bioavailability of labelled phylloquinone from the capsule ('meal effect'). AUC values were checked for normal distribution by observing a quintile-quintile plot. AUC for tracer measurements were compared using linear regression with fixed effects for meal, subject and period.

Tracer concentration was calculated as

$$
\text { Tracer concentration }=\frac{\left(R_{\mathrm{M}+1}(t)-R_{\mathrm{M}+1}(0)\right)}{1+\left(R_{\mathrm{M}+1}(t)-R_{\mathrm{M}+1}(0)\right)} \times C(t),
$$

where $R_{\mathrm{M}+1}$ is the ratio of $\mathrm{M}+1$ to $\mathrm{M}$ and at baseline $(0)$ and subsequent time points $(t) . C(t)$ is the concentration of total (i.e. labelled + unlabelled) phylloquinone, assessed by HPLC.

For comparisons of the bioavailability of phylloquinone from the meals, a different approach was taken. In each instance, if the absorption profile with time of phylloquinone from the meal were the same as that of the tracer, then the relationship between them would be linear and with a 1:1 ratio after normalisation for the dose given by adjusting concentrations for the amount of phylloquinone provided as tracer or in the meal. By measuring the slope of regressions between normalised concentration of tracer and tracee from the meal, it was possible to measure the relative absorption of the phylloquinone from each meal compared with the tracer. This 'matrix effect' describes the extraction efficiency of phylloquinone from the meal. Data manipulation was performed in Excel (Microsoft, Seattle, WA, USA) and statistics were performed using STATA version 9.1 (StataCorp LP, College Station, TX, USA).

\section{Results}

Mean baseline plasma phylloquinone concentration was $0 \cdot 35$ (SD $0 \cdot 30)$ nmol/l. Mean baseline intra-individual CV was $48 \%$. The maximum total plasma phylloquinone increment in any subject was $2.5 \mathrm{nmol} / \mathrm{l}$.

Phylloquinone in test meals measured by HPLC was $19.9 \mu \mathrm{g}$ in the convenience meal, $26 \cdot 3 \mu \mathrm{g}$ in the cosmopolitan meal and $33.0 \mu \mathrm{g}$ in the animal-oriented meal. The CV of results for duplicate extraction and analyses was $<4 \%$. For subsequent calculations, the measured meal phylloquinone content was used rather than that calculated from food tables.

The means of tracer AUC measurements were 0.88 (SD 0.43), $1.30(\mathrm{SD} 0.48)$ and $1.13(\mathrm{SD} 0.60) \mathrm{nmol} / \mathrm{l} \times \mathrm{h}$ for the convenience, cosmopolitan and animal-oriented meals, respectively. Individual values are shown in Table 2 . Significantly more phylloquinone tracer was absorbed when consumed with the cosmopolitan and animal-oriented meals than the convenience meal ( $P=0.001$ and 0.035 , respectively). We did not detect any significant difference between the cosmopolitan and animal-oriented meals $(P=0 \cdot 120)$. There were no significant differences in AUC between sexes, calculated using Student's $t$ test (convenience $P=0.83$, cosmopolitan $P=0 \cdot 88$, animal-oriented $P=0 \cdot 81$ ). Calculation of AUC between $0-5 \mathrm{~h}$ and $5-8 \mathrm{~h}$ tested the possible influence of the $5 \mathrm{~h}$ snack on appearance of tracer phylloquinone in plasma. However, differences between meals in tracer absorption were similar before and after the snack. Profiles of plasma tracer against time are shown in Fig. 1.

Table 2. Tracer area under the curve (AUC) values for each individual and each meal

\begin{tabular}{lccc}
\hline & \multicolumn{3}{c}{ Tracer AUC $(\mathrm{nmol} / \mathrm{l} \times \mathrm{h})$} \\
\cline { 2 - 4 } Subject & Convenience & Cosmopolitan & Animal-oriented \\
\hline A & 0.81 & 1.11 & 0.85 \\
$\mathrm{~B}$ & 0.64 & 0.94 & 0.84 \\
$\mathrm{C}$ & 1.04 & 1.71 & 1.31 \\
$\mathrm{D}$ & 2.04 & 1.87 & 2.44 \\
$\mathrm{E}$ & 0.94 & 2.03 & 1.51 \\
$\mathrm{H}$ & 0.30 & 1.11 & 0.45 \\
$\mathrm{I}$ & 0.97 & 0.94 & 0.96 \\
$\mathrm{~J}$ & 0.51 & 0.83 & 0.57 \\
K & 0.82 & 1.02 & 1.59 \\
L & 0.78 & 1.99 & 1.49 \\
M & 0.69 & 0.64 & 0.27 \\
$\mathrm{~N}$ & 1.03 & 1.40 & 1.23 \\
\hline
\end{tabular}




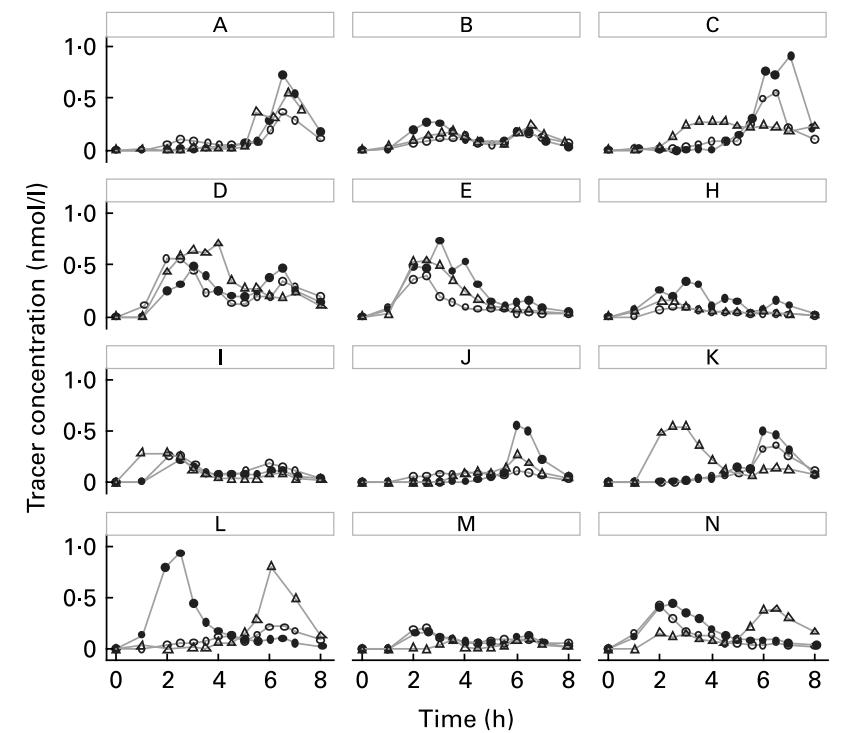

Fig. 1. $(A-N)$ Plasma phylloquinone tracer concentration $v$. time profiles for each subject, after oral administration of $20 \mu \mathrm{g}{ }^{13} \mathrm{C}$-labelled phylloquinone consumed together with the convenience meal $(\bigcirc)$, cosmopolitan meal $(\bullet)$, or animal-oriented meal $(\triangle)$.

Means of the slopes of the relationship between tracer and meal tracee after adjustment for dose were 1.88 (SD 0.81), 0.59 (SD 0.32) and 0.43 (SD 0.40) for convenience, cosmopolitan and animal-oriented meals, respectively. Final relative bioavailability values (Table 3 ) between meals were calculated by multiplying values for the matrix and meal effects and are expressed relative to the convenience meal.

\section{Discussion}

The primary aim of the present study was to develop and apply a stable isotope-based method to measure phylloquinone bioavailability. We proposed a method using ${ }^{13} \mathrm{C}$-labelled tracer as a standard, taken at the same time as a test meal. Changes in plasma phylloquinone isotopic enrichment could then be used to calculate relative bioavailability of phylloquinone from the meals. However, dominance of the meal effect resulted in significant differences in tracer absorption between the meals. As a consequence, it was not possible to use the tracer as a global standard by which to compare phylloquinone absorption. An alternative approach was adopted where relative bioavailability of phylloquinone from the meals was assessed on the basis of the relationship between tracer and tracee absorption profile with time. Thus, two, separate but interacting, determinants to bioavailability can be considered.
Firstly, meal composition affects the bioavailability of free phylloquinone. This meal effect is the result of the meal modifying conditions within the gut and affecting digestion and/or absorption, and the potential enhancers or inhibitors of absorption. The second determinant, matrix effects or bioaccessibility, relate to the extraction of phylloquinone from the meal constituents. The appearance in plasma of ${ }^{13} \mathrm{C}$-labelled phylloquinone was used to determine meal effects, whereas the relationship between tracer and tracee phylloquinone was used to determine matrix effects. A final relative bioavailability value for each of the meals was determined as the product of the matrix and meal effects.

Absorption of phylloquinone from the capsule was significantly lower when taken with the convenience meal compared with the other meals. Such variation in absorption between meals has also been observed for stable isotope-labelled vitamin $\mathrm{E}^{(26)}$. Various meal factors such as viscosity, particle size, meal volume, macronutrient content and energy density determine gastric emptying and intestinal transit ${ }^{(40)}$, and these may affect phylloquinone bioavailability. To minimise differences in gastric emptying between the meals, all were balanced for fibre content, energy and percentage of energy from fat, protein and carbohydrate. However, the convenience meal had a $50 \%$ greater energy density that may have influenced phylloquinone absorption. Borel et al. ${ }^{(41)}$ investigated the effect of emulsified fat globule size on the absorption of vitamins $\mathrm{A}$ and $\mathrm{E}$ and concluded that the size of the particles does not affect absorption. Fat is required to stimulate bile secretion that is necessary for the absorption of phylloquinone ${ }^{(42)}$. Butter increased phylloquinone absorption from spinach 3-fold ${ }^{(19)}$, but another study reported no difference in phylloquinone absorption between lettuce consumed with either 30 or $45 \%$ energy from fat ${ }^{(20)}$. Meals in the present study contained similar amounts of fat, thus total fat is unlikely to explain the differences in absorption between meals. The fatty acid composition of a meal may affect absorption and plasma response by changing the physical characteristics of mixed micelles and/or influencing postprandial lipid metabolism. Chylomicrons are the major carrier of postprandial phylloquinone ${ }^{(43)}$ and chylomicron remnants transport phylloquinone to both liver and also bone ${ }^{(44)}$. The size of mixed micelles may be important since longer chain fatty acids reduced phylloquinone absorption ${ }^{(45)}$. PUFA decreased phylloquinone absorption in in vitro $^{(45)}$ and rat ${ }^{(46)}$ experiments, possibly through a greater affinity of the mixed micelle for phylloquinone decreasing transfer across the enterocyte. More recent studies in human subjects have shown that a PUFA-rich maize oil diet resulted in lower plasma phylloquinone compared with a diet enriched with

Table 3. Summary of meal and matrix effects and combined relative bioavailability values for the three test meals

\begin{tabular}{lccccc}
\hline Meal & Meal effect ${ }^{\star}$ & Meal effect (normalised) & Matrix effect $\dagger$ & Matrix effect (normalised) & Total effectł \\
\hline Convenience & 0.88 & 1.00 & 1.88 & 1.00 & 1.00 \\
Cosmopolitan & 1.30 & 1.48 & 0.59 & 0.31 & 0.46 \\
Animal-oriented & 1.13 & 1.28 & 0.43 & 0.23 & 0.29 \\
\hline
\end{tabular}

Values are normalised to the convenience meal.

* Meal effect refers to the effect of meal on absorption of tracer vitamin $\mathrm{K}_{1}$ calculated from area under the curve measurements of plasma tracer concentration.

† Matrix effect refers to the bioavailability of vitamin $\mathrm{K}_{1}$ from within the food matrix, relative to the tracer.

$¥$ The total effect is calculated as the product of the meal and matrix effects. 
olive/sunflower oil ${ }^{(47)}$. In the present study, the convenience meal contained more than 2-fold greater PUFA $(37 \%$ of total fat) than both the cosmopolitan $(19 \%)$ and animaloriented meals $(14 \%)$. Inhibition of phylloquinone uptake or altered postprandial metabolism by the high PUFA convenience meal could explain the lower absorption of phylloquinone from the capsule. Evidence suggests that vitamin E may affect phylloquinone status in rats ${ }^{(48,49)}$; however, other studies have shown that effects are limited to tissue status, not plasma status, both in animal ${ }^{(50)}$ and in human studies ${ }^{(51)}$, thus it is likely that any effect is related to metabolism rather than absorption ${ }^{(47,52)}$. In the present study, the vitamin $\mathrm{E}$ content of each meal, calculated using food composition tables, was $11 \cdot 0,5 \cdot 3$ and $5.8 \mathrm{mg}$ for the convenience, cosmopolitan and animal-oriented meals, respectively.

Observation of the tracer profiles in Fig. 1 reveals that in the majority of cases, an individual's plasma tracer concentration profile shows a similar pattern for each test meal, and suggests that the differences in tracer profiles reflect genetic or physiological differences between individuals, e.g. transfer of phylloquinone across the enterocyte or chylomicron metabolism (apo E genotype). High intra-individual consistency in absorption profiles of carotenoids has also been observed ${ }^{(53)}$. Although in general tracer profiles within individuals were similar for the different meals, subjects $\mathrm{K}, \mathrm{L}$ and $\mathrm{N}$ showed substantial intra-individual differences in tracer absorption profile between the meals that may have confounded the results. As far as practicable external influences on digestion and absorption were controlled (such as previous meals, fasting and seating position), it is possible that these may have affected the absorption profile. In addition, particularly where absorption was apparently delayed, tracer concentration remained elevated beyond the $8 \mathrm{~h}$ duration of the experiment thus similar future studies might consider increasing the sampling period. These observations demonstrate that consideration should be given to potential variability of the absorption profile in bioavailability studies, particularly where absorption is assessed on the basis of a measurement at a single time point ${ }^{(54)}$, and further supports the importance of crossover studies. Although generally there was some consistency in the extent of tracer absorption between the different meals for the same individual (assessed by rank; Table 2), the potential variability in absorption of phylloquinone from the same meal eaten on different occasions for a given individual is unknown and may have influenced the data. A single study has reported the intra-individual variation of phylloquinone absorption, albeit of a very large dose of a pharmaceutical preparation of phylloquinone $(2.2 \mu \mathrm{mol}$ Konakion). CV of the AUC measurements for three individuals each measured on three occasions were 18,7 and $9 \%{ }^{(19)}$.

In a number of individuals, tracer phylloquinone peaked between 5 and $8 \mathrm{~h}$, or a second smaller peak was observed, apparently in response to the $5 \mathrm{~h}$ snack. Although there were no differences in AUC before and after the snack, the snack may influence the plasma tracer profile. In some individuals, the physiological response to the snack may be the release of partially absorbed phylloquinone into the circulation. Dueker et al. ${ }^{(55)}$ reported a similar observation with a second plasma peak of labelled $\beta$-carotene. A comparable phenomenon has also been reported with fatty acids, where fatty acids consumed during an initial meal appear in the circulation after a second meal a number of hours later ${ }^{(56,57)}$. An alternative explanation for the second peak is hepatic secretion of VLDL containing phylloquinone ${ }^{(27,43,58)}$.

In contrast to tracer absorption, and on the basis of the matrix effect alone, absorption of phylloquinone from the convenience meal was more than 3-fold than that from the cosmopolitan and animal-oriented meals. While the magnitude of this difference was reduced with the inclusion of the meal effect (tracer data), total relative bioavailability remained greater from the convenience meal. Greater absorption of phylloquinone from the convenience meal may be expected given the sources of phylloquinone. In the convenience meal, it can be estimated that more than $80 \%$ of the phylloquinone was in the oil phase, whereas in the cosmopolitan and animal-oriented meals only 10 and $20 \%$ of phylloquinone was in oil, respectively. Conversely, the majority of phylloquinone in the cosmopolitan and animaloriented meals was sited within a vegetable matrix where it is tightly bound to the thylakoid membranes and may be less bioavailable because cell walls and membranes must be digested before absorption. Although it is generally assumed that fat-soluble vitamin absorption is greater from fat than from vegetables, there have been few direct comparisons ${ }^{(59)}$. Previous studies to compare the bioavailability of phylloquinone from oil and vegetables have shown conflicting results. In one study, absorption, calculated by $24 \mathrm{~h}$ AUC, was reported to be significantly greater from oil than from broccoli $^{(23)}$ but an earlier study, which measured absorption of phylloquinone from multiple meals over $5 \mathrm{~d}$, found no difference in absorption between these two sources ${ }^{(22)}$. A number of caveats are applicable to our interpretation of the matrix effect data. Firstly, due to low phylloquinone content of the meals and low absorption, the plasma phylloquinone content attributable to phylloquinone from the meal was towards the lower end of analytical limits. Plasma phylloquinone concentration from the meal across the time course of the experiment was between 0.2 and $1 \mathrm{nmol} / \mathrm{l}$. Secondly, and as discussed earlier in relation to the tracer data, there was variability in the pattern of phylloquinone appearance in plasma and in responses with the different meals, both of which may have influenced our interpretation of the matrix effect. Thirdly, although the mixed meal provides the opportunity to assess the combined impact of foods, interpretation of these effects is complicated by the many interacting factors.

Previous phylloquinone absorption studies have primarily tested single foods, either individually or in combination with untypical food combinations. The meal-based method described here was an attempt to use a less subjective approach to the design of test meals with the aim that they represent more accurately meals in a free-living situation in which food components may interact to negate effects observed in experiments with individual foods. The three meals in the present study were designed using the characteristics of dietary clusters identified in a national nutrition survey. The use of dietary analysis in this way provides a basis for the design of test meals in bioavailability experiments that can be used to probe relationships between dietary intake and plasma response and/or status. The meals were designed to contain equal amounts of phylloquinone, with the major difference between the meals, the sources of phylloquinone. However, direct analysis of meals revealed 
variation in the measured value compared with that calculated from nutrient tables. The observed discrepancy however is not unusual; the phylloquinone content of foods is known to be highly variable and affected by heating ${ }^{(60)}$. Furthermore, a comparison of the phylloquinone content of ten meals calculated by two nutrient databases compared with direct analysis showed variation of up to $89 \%{ }^{(61)}$.

In summary, we have investigated a meal-based approach to measurements of absorption, which is more relevant to the consumption of foods in a free-living population. The apparent dominance of the meal effect showed that different meals affect absorption of phylloquinone, although the mechanism is unknown. Notwithstanding the potential limitations, the data also suggest that phylloquinone may be more bioavailable from oils and fats than from vegetable sources.

\section{Acknowledgements}

We would like to acknowledge the UK Food Standards Agency for funding this work (project number N05050). We would like to thank Louise McKenna for assistance in sample extraction and analysis, and the volunteers for participating in the study. We also thank Dr Adrian Mander and Mark Chatfield for statistical advice. There are no conflicts of interest. K. S. J., L. J. C. B., A. M. S., C. J. P. and W. A. C. all contributed to the design of the study. K. S. J. performed the actual study including meal design and preparation, volunteer work, GC/MS analysis of plasma, food extractions, and data analysis. L. Y. W. performed all the HPLC analysis. K. S. J. drafted the manuscript with input from all co-authors.

\section{References}

1. Department of Health (1991) Dietary Reference Values for Food Energy and Nutrients for the United Kingdom. Report on Health and Social Subjects no. 41. London: HMSO.

2. Deutsche Gesellschaft für Ernährung, Österreichische Gesellschaft für Ernährung, Schweizerische Gesellschaft für Ernährungsforschung, Schweizerische Vereinigung für Ernährung (German Society for Nutrition, Austrian Society for Nutrition, Swiss Society for Nutrition Research, Swiss Association for Nutrition) (2000) Referenzwerte D-A-C (Reference Values D-A-C). In Referenzwerte für die Nährstoffzufuhr (Reference Values for Nutrient Intakes). Frankfurt/Main: Umschau Braus Verlag.

3. Thane CW, Bolton-Smith C \& Coward WA (2006) Comparative dietary intake and sources of phylloquinone (vitamin $\mathrm{K}_{1}$ ) among British adults in 1986-7 and 2000-1. Br J Nutr 96, 1105-1115.

4. Binkley NC, Krueger DC, Engelke JA, et al. (2000) Vitamin K supplementation reduces serum concentrations of undergamma-carboxylated osteocalcin in healthy young and elderly adults. Am J Clin Nutr 72, 1523-1528.

5. Bügel S, Sørenson AD, Hels O, et al. (2007) Effect of phylloquinone supplementation on biochemical markers of vitamin $\mathrm{K}$ status and bone turnover in postmenopausal women. $\mathrm{Br} J$ Nutr 97, 373-380.

6. Cranenburg ECM, Schurgers LJ \& Vermeer C (2007) Vitamin K: the coagulation vitamin that became omnipotent. Thrombo Haemost 98, 120-125.

7. Booth SL, Broe KE, Gagnon DR, et al. (2003) Vitamin K intake and bone mineral density in women and men. Am $J$ Clin Nutr 77, 512-516.
8. Feskanich D, Weber P, Willett WC, et al. (1999) Vitamin K intake and hip fractures in women: a prospective study. $A m J$ Clin Nutr 69, 74-79.

9. Booth SL, Tucker KL, Chen H, et al. (2000) Dietary vitamin K intakes are associated with hip fracture but not with bone mineral density in elderly men and women. Am J Clin Nutr 71, 1201-1208.

10. Binkley N, Harke J, Krueger D, et al. (2008) Vitamin K treatment reduces undercarboxylated osteocalcin but does not alter bone turnover, density or geometry in healthy postmenopausal North American women. J Bone Miner Res (epublication ahead of print version 29 December 2008).

11. Booth SL, Dallal G, Shea MK, et al. (2008) Effect of vitamin K supplementation on bone loss in elderly men and women. J Clin Endocrinol Metab 93, 1217-1223.

12. Cheung AM, Tile L, Lee Y, et al. (2008) Vitamin K supplementation in postmenopausal women with osteopenia (ECKO trial): a randomized controlled trial. PLoS Medicine 5, e196.

13. Thane CW, Wang LY \& Coward WA (2006) Plasma phylloquinone (vitamin $\mathrm{K}_{1}$ ) concentration and its relationship to intake in British adults aged 19-64 years. Br J Nutr 96, 1116-1124.

14. Khan T, Wynne H, Wood P, et al. (2004) Dietary vitamin K influences intra-individual variability in anticoagulant response to warfarin. Br J Haematol 124, 348-354.

15. Couris R, Tataronis G, McCloskey W, et al. (2006) Dietary vitamin $\mathrm{K}$ variability affects international normalized ratio (INR) coagulation indices. Int J Vit Nutr Res 76, 65-74.

16. Custódio das Dôres SM, Booth SL, Aújo Martini L, et al. (2007) Relationship between diet and anticoagulant response to warfarin: a factor analysis. Eur J Nutr 46, 147-154.

17. Duggan P, Cashman KD, Flynn A, et al. (2004) Phylloquinone (vitamin $\mathrm{K}_{1}$ ) intakes and food sources in 18-64-year-old Irish adults. Br J Nutr 92, 151-158.

18. Bolton-Smith C, Price RJ, Fenton ST, et al. (2000) Compilation of a provisional UK database for the phylloquinone (vitamin $\mathrm{K}_{1}$ ) content of foods. Br J Nutr 83, 389-399.

19. Gijsbers BL, Jie KS \& Vermeer C (1996) Effect of food composition on vitamin $\mathrm{K}$ absorption in human volunteers. $\mathrm{Br} \mathrm{J}$ Nutr 76, 223-229.

20. Garber AK, Binkley NC, Krueger DC, et al. (1999) Comparison of phylloquinone bioavailability from food sources or a supplement in human subjects. J Nutr 129, 1201-1203.

21. Schurgers LJ \& Vermeer C (2000) Determination of phylloquinone and menaquinones in food. Effect of food matrix on circulating vitamin K concentrations. Haemostasis 30, 298-307.

22. Booth SL, O'Brien-Morse ME, Dallal GE, et al. (1999) Response of vitamin $\mathrm{K}$ status to different intakes and sources of phylloquinone-rich foods: comparison of younger and older adults. Am J Clin Nutr 70, 368-377.

23. Booth SL, Lichtenstein AH \& Dallal GE (2002) Phylloquinone absorption from phylloquinone-fortified oil is greater than from a vegetable in younger and older men and women. $J$ Nutr 132, 2609-2612.

24. Yeum K-J \& Russell RM (2002) Carotenoid bioavailability and bioconversion. Ann Rev Nutr 22, 483-504.

25. Bates CJ, Jones KS \& Bluck LJ (2004) Stable isotope-labelled vitamin $\mathrm{C}$ as a probe for vitamin $\mathrm{C}$ absorption by human subjects. Br J Nutr 91, 699-705.

26. Jeanes YM, Hall WL, Ellard S, et al. (2004) The absorption of vitamin $\mathrm{E}$ is influenced by the amount of fat in a meal and the food matrix. Br J Nutr 92, 575-579.

27. Erkkilä AT, Lichtenstein AH, Dolnikowski GG, et al. (2004) Plasma transport of vitamin $\mathrm{K}$ in men using deuterium-labeled collard greens. Metabolism 53, 215-221.

28. Dolnikowski GG, Sun Z, Grusak MA, et al. (2002) HPLC and GC/MS determination of deuterated vitamin $\mathrm{K}$ (phylloquinone) in human serum after ingestion of deuterium-labeled broccoli. J Nutr Biochem 13, 168-174. 
29. Kurilich AC, Britz SJ, Clevidence BA, et al. (2003) Isotopic labeling and LC-APCI-MS quantification for investigating absorption of carotenoids and phylloquinone from kale (Brassica oleracea). J Agric Food Chem 51, 4877-4883.

30. Jones KS, Bluck LJC \& Coward WA (2006) Analysis of isotope ratios in vitamin $\mathrm{K}_{1}$ (phylloquinone) from human plasma by gas chromatography mass spectrometry. Rapid Commun Mass Spectrom 20, 1894-1898.

31. Jones KS, Bluck LJC, Wang LY, et al. (2007) A dual stable isotope approach for the simultaneous measurement of vitamin $\mathrm{K}_{1}$ (phylloquinone) kinetics and absorption. Eur $J$ Clin Nutr 62, 1273-1281.

32. Fahey MT, Thane CW, Bramwell GD, et al. (2007) Conditional Gaussian mixture modelling for dietary pattern analysis. J R Stat Soc Ser A Stat Soc 170, 1-18.

33. Paul AA \& Southgate DAT (1978) McCance and Widdowson's The Composition of Foods, 4th ed. London: HMSO.

34. Holland B, Unwin ID \& Buss DH (1988) Cereals and Cereal Products: Third Supplement to McCance \& Widdowson's The Composition of Foods, 4th ed. Nottingham: Royal Society of Chemistry Ministry of Agriculture, Fisheries and Food.

35. Holland B, Unwin ID \& Buss DH (1989) Milk Products and Eggs: Fourth Supplement to McCance \& Widdowson's The Composition of Foods, 4th ed. Cambridge: Royal Society of Chemistry Ministry of Agriculture, Fisheries and Food.

36. Food Standards Agency (2002) McCance and Widdowson's The Composition of Foods, 6th ed. Cambridge: Royal Society of Chemistry.

37. Booth SL, Davidson KW \& Sadowski JA (1994) Evaluation of an HPLC method for the determination of phylloquinone (vitamin $\mathrm{K}_{1}$ ) in various food matrices. J Agric Food Chem 42, 295-300.

38. Wang LY, Bates CJ, Yan L, et al. (2004) Determination of phylloquinone (vitamin $\mathrm{K}_{1}$ ) in plasma and serum by HPLC with fluorescence detection. Clin Chim Acta 347, 199-207.

39. Bluck LJC \& Coward WA (1997) Peak measurement in gas chromatographic mass spectrometric isotope studies. $J$ Mass Spectrom 32, 1212-1218.

40. Low AG (1990) Nutritional regulation of gastric secretion, digestion and emptying. Nutr Res Rev 3, 229-252.

41. Borel P, Pasquier B, Armand M, et al. (2001) Processing of vitamin $\mathrm{A}$ and $\mathrm{E}$ in the human gastrointestinal tract. Am J Physiol Gastrointest Liver Physiol 280, G95-G103.

42. Shearer MJ, McBurney A \& Barkhan P (1974) Studies on the absorption and metabolism of phylloquinone (vitamin $\mathrm{K}_{1}$ ) in man. Vitam Horm 32, 513-542.

43. Lamon-Fava S, Sadowski JA, Davidson KW, et al. (1998) Plasma lipoproteins as carriers of phylloquinone (vitamin $\mathrm{K}_{1}$ ) in humans. Am J Clin Nutr 67, 1226-1231.

44. Niemeier A, Kassem M, Toedter K, et al. (2005) Expression of LRP1 by human osteoblasts: a mechanism for the delivery of lipoproteins and vitamin $\mathrm{K}_{1}$ to bone. J Bone Miner Res 20, 283-293.
45. Hollander D \& Rim E (1976) Factors affecting the absorption of vitamin $\mathrm{K}-1$ in vitro. Gut 17, 450-455.

46. Hollander D, Rim E \& Muralidhara KS (1977) Vitamin $K_{1}$ intestinal absorption in vivo: influence of luminal contents on transport. Am J Physiol Endocrinol Metab 232, E69-E74.

47. Schurgers LJ, Shearer MJ, Soute BA, et al. (2002) Novel effects of diets enriched with corn oil or with an olive oil/sunflower oil mixture on vitamin $\mathrm{K}$ metabolism and vitamin $\mathrm{K}$-dependent proteins in young men. $J$ Lipid Res $\mathbf{4 3}, 878-884$

48. Alexander GD \& Suttie JW (1999) The effect of vitamin E on vitamin $\mathrm{K}$ activity. FASEB $J$ 40, 430-431.

49. Mitchell GV, Cook KK, Jenkins MY, et al. (2001) Supplementation of rats with a lutein mixture preserved with vitamin $\mathrm{E}$ reduces tissue phylloquinone and menaquinone-4. Int $J$ Vitam Nutr Res 71, 30-35.

50. Tovar A, Ameho CK, Blumberg JB, et al. (2006) Extrahepatic tissue concentrations of vitamin $\mathrm{K}$ are lower in rats fed a high vitamin E diet. Nutr Metab 3, 29.

51. Booth SL, Golly I, Sacheck JM, et al. (2004) Effect of vitamin E supplementation on vitamin $\mathrm{K}$ status in adults with normal coagulation status. Am J Clin Nutr 80, 143-148.

52. Traber MG (2008) Vitamin E and K interactions - a 50-yearold problem. Nutr Rev 66, 624-629.

53. Faulks RM \& Southon S (2005) Challenges to understanding and measuring carotenoid bioavailability. Biochim Biophys Acta 1740, 95-100.

54. Schurgers LJ, Teunissen KJF, Hamulyak K, et al. (2007) Vitamin K-containing dietary supplements: comparison of synthetic vitamin $\mathrm{K}_{1}$ and natto-derived menaquinone-7. Blood 109, 3279-3283.

55. Dueker SR, Lin Y, Buchholz BA, et al. (2000) Long-term kinetic study of beta-carotene, using accelerator mass spectrometry in an adult volunteer. J Lipid Res 41, 1790-1800.

56. Fielding B, Callow J, Owen R, et al. (1996) Postprandial lipemia: the origin of an early peak studied by specific dietary fatty acid intake during sequential meals. Am J Clin Nutr 63, $36-41$.

57. Maillot F, Garrigue MA, Pinault M, et al. (2005) Changes in plasma triacylglycerol concentrations after sequential lunch and dinner in healthy subjects. Diabetes Metab 31, 69-77.

58. Schurgers LJ \& Vermeer C (2002) Differential lipoprotein transport pathways of K-vitamins in healthy subjects. Biochim Biophys Acta 1570, 27-32.

59. Parker RS, Swanson JE, You CS, et al. (1999) Bioavailability of carotenoids in human subjects. Proc Nutr Soc 58, 155-162.

60. Ferland G \& Sadowski JA (1992) Vitamin $\mathrm{K}_{1}$ (phylloquinone) content of edible oils: effects of heating and light exposure. J Agric Food Chem 40, 1869-1873.

61. McKeown NM, Rasmussen HM, Charnley JM, et al. (2000) Accuracy of phylloquinone (vitamin K-1) data in 2 nutrient databases as determined by direct laboratory analysis of diets. J Am Diet Assoc 100, 1201-1204. 